Proc. Indian Acad. Sci. (Chem. Sci.), Vol. 103, No. 5, October 1991, pp. 655-666.

(c) Printed in India.

\title{
Formation of lead pyrophosphate glass and the role of anion disproportionation ${ }^{\#}$
}

\author{
S ANANTHRAJ ${ }^{\dagger}$ and $\mathrm{K}$ J RAO* \\ Materials Research Centre, Indian Institute of Science, Bangalore 560012, India \\ 'Present address: Department of Chemistry, Central College, Bangalore University, \\ Bangalore 560001, India \\ MS received 8 March 1991

\begin{abstract}
Thermal, spectroscopic and electrical properties of lead pyrophosphate glass prepared by melt quenching have been examined. A model based on the structural disproportionation of the $\mathrm{P}_{2} \mathrm{O}_{7}^{4-}$ ions has been proposed and is shown to consistently explain all the observations. The equilibrium of various anionic species has been discussed on the basis of their electronegativities which are in turn related to their basicities.
\end{abstract}

Keywords. $\quad \mathrm{Pb}_{2} \mathrm{P}_{2} \mathrm{O}_{7}$ glass; anion disproportionation; molecular electronegativities.

\section{Introduction}

We have noted in our earlier publications (Ananthraj et al 1986,1988) that pyrophosphates form glasses very readily. This propensity of pyrophosphates towards vitrification appears to be a consequence of structural disproportionation of $\mathrm{P}_{2} \mathrm{O}_{7}^{4-}$ ions into various anionic species containing either long polymeric chains or closed rings. High Resolution (HR) Magic Angle Spinning Nuclear Magnetic Resonance studies (MAS NMR) of pyrophosphates (Prabhakar et al 1987) have lent support to this view. Specifically, silver pyrophosphate was investigated in crystalline and glassy forms and the properties of silver pyrophosphate glass were shown to be consistent with such a structural model (Ananthraj et al 1986; 1988). We have also suggested that the behaviour of other pyrophosphate glasses would be similar. Indeed some recent independent High Performance Liquid Chromatography (HPLC) investigations of lead pyrophosphate glass has confirmed the presence of many anionic species (Sales et al 1987,1989). The presence of chain phosphate units of varying lengths in phosphate glasses has been known through the early classic work of Van Wazer (1958). In this background we have now investigated the lead pyrophosphate glass in some details and have confirmed its similarity to silver pyrophosphate glasses. Since the equilibration of anionic species is of cardinal importance in the formation of phosphate glasses, we have examined this feature in lead pyrophosphate glass using a structural model based on disproportionation of pyrophosphate anions. We have also shown that the proportions of various anions are related to the electronegativities

\footnotetext{
\# Communication No. 129 from the Materials Research Centre

* For correspondence
} 
of the different anionic entities in the glass, which in turn are related to the acid-base equilibria.

\section{Experimental}

Lead pyrophosphate was prepared starting from lead nitrate by a double displacement reaction in solution. Lead pyrophosphate was then dried at $673 \mathrm{~K}$ for about six hours. The X-ray diffraction pattern of lead pyrophosphate (figure 1) thus prepared was found to compare well with literature data (ASTM Cards). Lead pyrophosphate was melted in a platinum crucible. The temperature of the melt was raised to about $1250 \mathrm{~K}$ and the melt was maintained at this temperature for an hour. It was poured on to a polished brass plate and quickly pressed using a brass block with polished surfaces. The brass plate was maintained at $320 \mathrm{~K}$ to prevent the vitrified discs from cracking. The resulting glasses were transparent and colourless and gave rise to typical amorphous patterns both in $\mathrm{X}$-ray and electron diffraction. The glassy samples which were annealed at about $520 \mathrm{~K}$ for 24 hours, were used for measuring various properties.

Heat capacities of lead pyrophosphate glass were determined on a Perkin-Elmer DSC-2 differential scanning calorimeter using sapphire as standard. A uniform heating rate of $10 \mathrm{~K} \mathrm{~min}^{-1}$ was used throughout the measurements. The glass transition temperature $T_{g}$, was evaluated as the intersection point of the extended linear regions in the specific heat $\left(C_{p}\right)$ vs temperature $(T)$ plot around the glass transition elbow.

Infrared spectra of both crystalline and glassy samples were obtained in $\mathrm{KBr}$ pellets and recorded at laboratory temperature on a Perkin-Elmer $590 \mathrm{IR}$ spectrometer from 300 to $1200 \mathrm{~cm}^{-1}$.

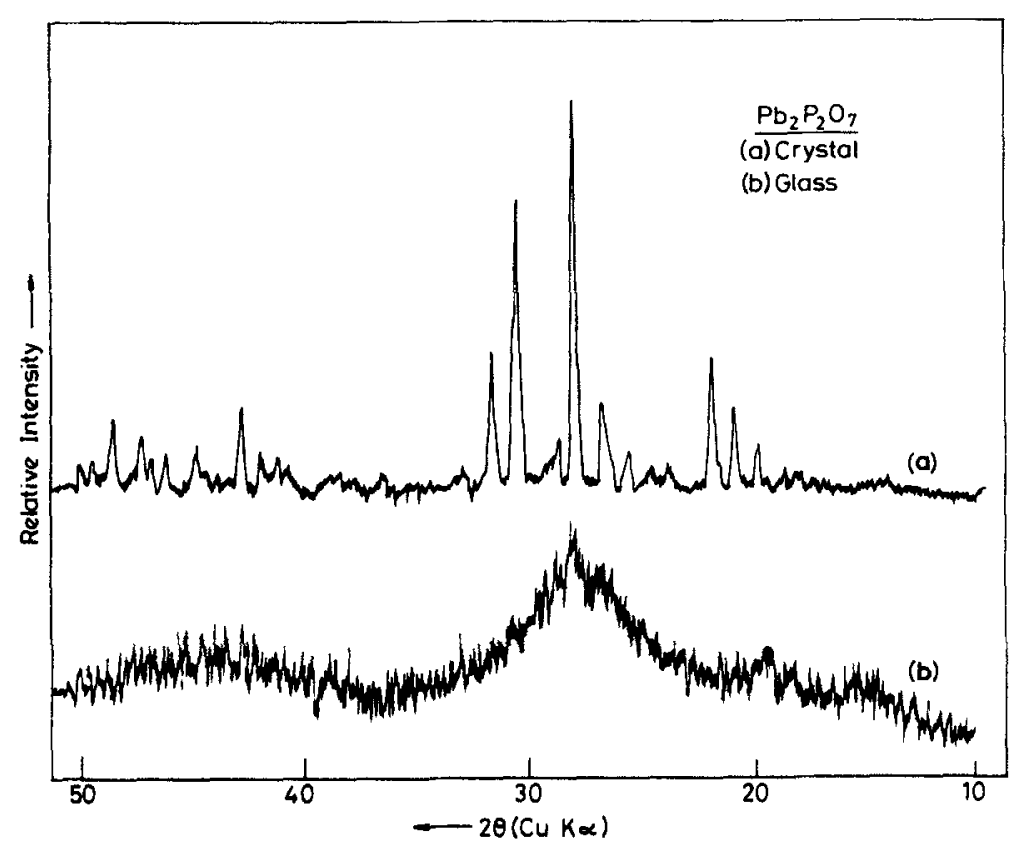

Figure 1. Powder diffraction patterns for $\mathrm{Pb}_{2} \mathrm{P}_{2} \mathrm{O}_{7}$ (a) crystal and (b) glass. 
For making $\mathrm{AC}$ conductivity, $\sigma_{\mathrm{AC}}$, measurements, lead pyrophosphate glass discs (annealed at $520 \mathrm{~K}$ ) were coated with gold electrodes by sputtering. AC conductance $\left(G_{p}\right)$ for the lead pyrophosphate glassy sample was measured as a function of both temperature $(300-760 \mathrm{~K})$ and frequency $(1-100 \mathrm{KHz})$ using a GR Impedence bridge, model GR $1680 \mathrm{~A}$, coupled externally with a GR Oscillator using a signal strength of $5 \mathrm{~V}$ ( $\mathrm{rms}$ ). Conductivities were calculated from the known dimensions of the sample. $\sigma_{\mathrm{AC}}$ was also evaluated using a Hewlett Packard LCR bridge model 4274 A.

\section{Results and discussions}

\subsection{Structural studies}

Formation of single-phase lead pyrophosphate was confirmed using X-ray diffraction. Powder diffraction patterns of lead pyrophosphate crystal and glass are shown in figure 1. Lead pyrophosphate crystals were also obtained after recrystallization of the glass which occurs at $710 \mathrm{~K}$. The diffraction pattern of the crystalline powder was found to match very well with literature report (ASTM Cards).

High resolution electron micrographs of the glass and crystalline materials are shown in figures 2 and 3. The grain dimension in the high-resolutin electron micrograph of the glass is less than $1 \mathrm{~nm}$ across. The glass therefore has no detectable micro-heterogenity like other network glasses. Selected area diffraction of the crystallized sample is also included in figure $3 \mathrm{a}$, for $\langle 001\rangle$ orientation. Lattice parameters $(a=6.9 \AA, c=12.75 \AA)$ compare well with the distances calculated from single-crystal X-ray work.

The diffraction pattern obtained from $\langle 010\rangle$ orientation (figure $3 b$ ) reveals streaking and the presence of close pairs of diffraction spots, possibly arising from twins.



Figure 2. Electron micrograph along with the diffraction pattern (inset) for $\mathrm{Pb}_{2} \mathrm{P}_{2} \mathrm{O}_{7}$ glass. 

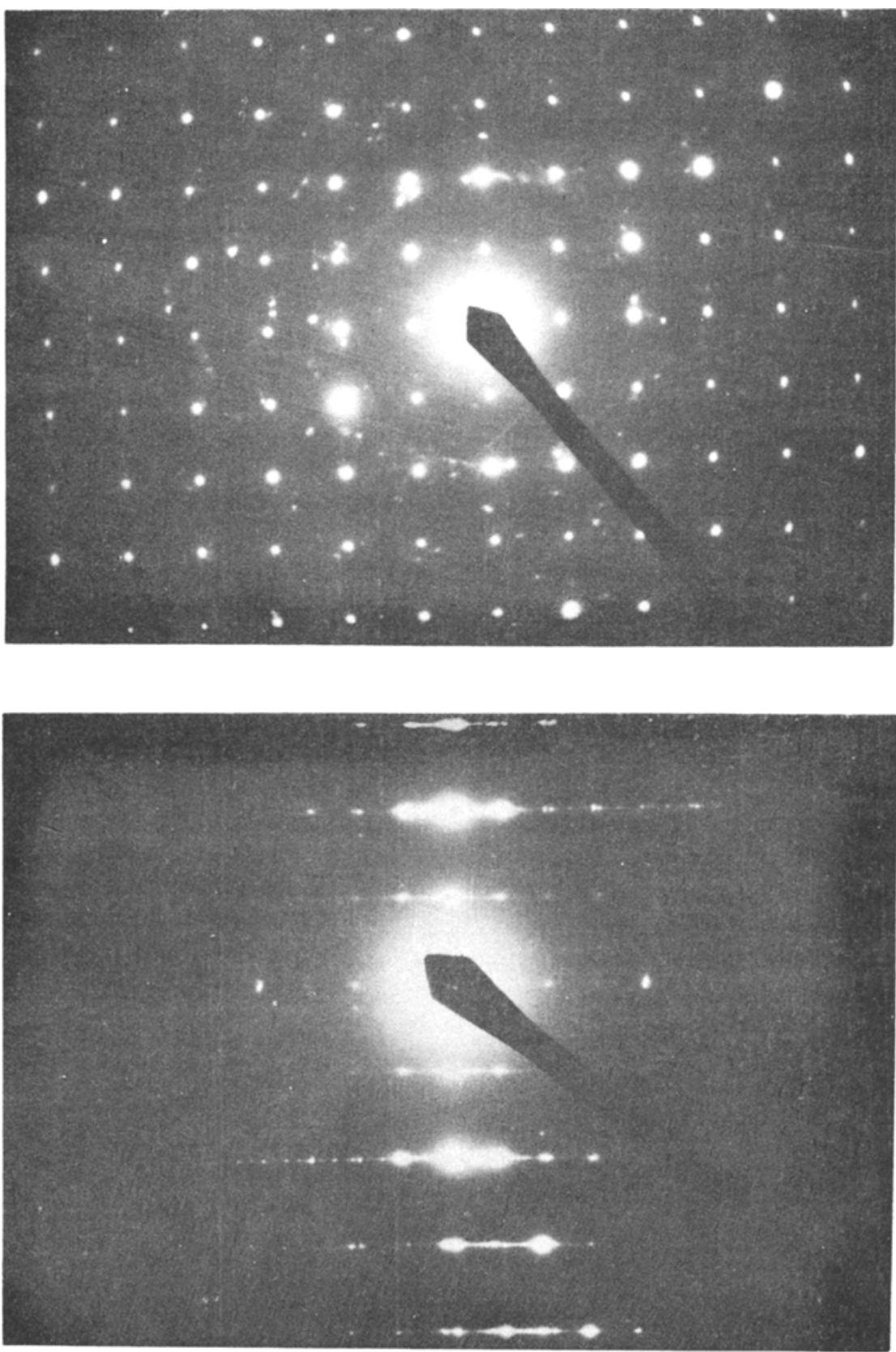

Figure 3. Electron diffraction pattern of $\mathrm{Pb}_{2} \mathrm{P}_{2} \mathrm{O}_{7}$ crystal for $\langle 001\rangle$ and $\langle 010\rangle$ orientations.

It also consists of spots arising due to diffraction from neighbouring grains with entirely different orientations. Twinning as seen in $\langle 010\rangle$ orientation is also evident from a high-resolution image of the crystallized sample shown in figure 4 . While the magnified bright-field image shows bands formed during recrystallization, the HREM image indicates variation of the widths of the layers formed due to twinning. We 


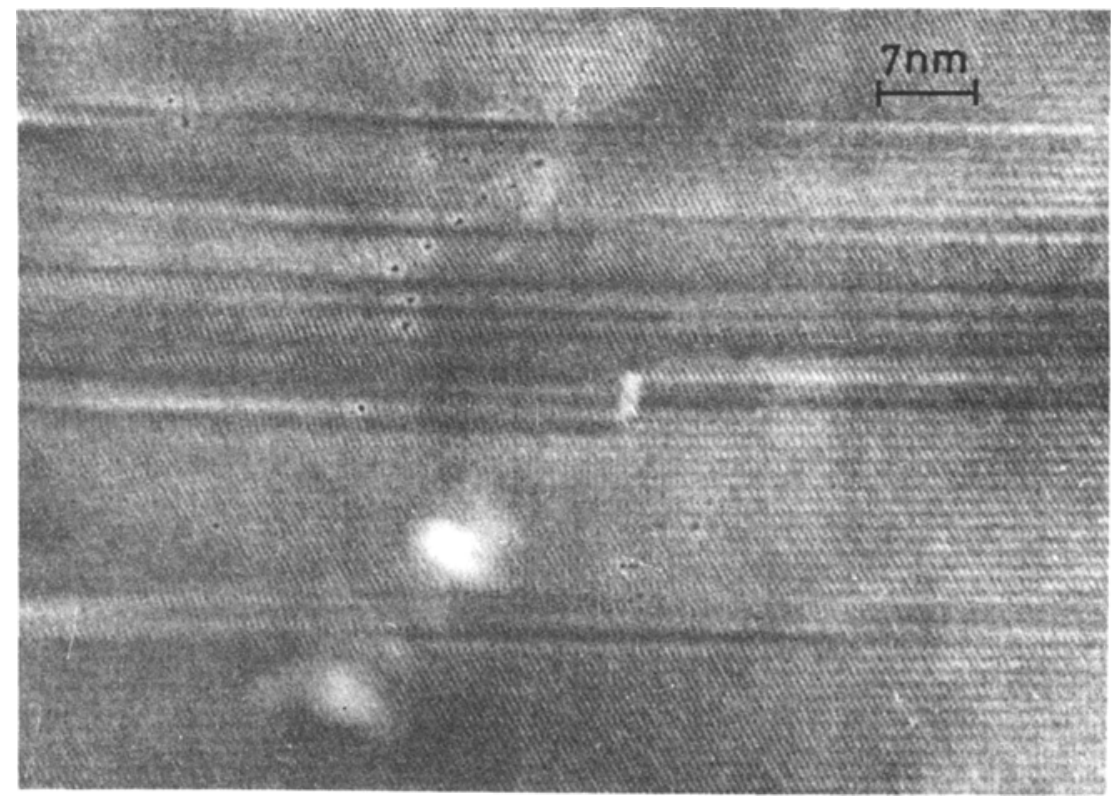

Figure 4. High resolution electron mirograph image of crystallized $\mathrm{Pb}_{2} \mathrm{P}_{2} \mathrm{O}_{7}$ showing stacking disorder in $\langle 010\rangle$ orientation.

show later that during recrystallization a variety of anionic species have to undergo re-grouping and structural reformation to produce pyrophosphate anions (corner linked ditetrahedra). Since this process requires diffusion of anionic species although on a limited scale, twinning is likely to occur during re-ordering of anions on the lattice positions. However, diffraction effects similar to those in figures 3 and 4 can result from stacking faults also and their formation during crystallization can also be similarly visualized. Nevertheless, electron miroscopy strongly suggests that a complex schedule of structural rearrangements precedes crystallization.

\subsection{Thermal properties}

Heat capacities measured up to and slightly above the glass transition temperature for lead pyrophosphate glass are shown in figure 5 . The heat capacities have been obtained as averages of several measurements. $T_{g}$ has been found to be $638 \mathrm{~K}$ and the glass transition is both well defined and associated with a hump just above $T_{g}$. $\Delta C_{p}$, the jump in heat capacity at $T_{g}$ is found to be about $80 \mathrm{JK}^{-1} \mathrm{~mol}^{-1}$. The variation of heat capacities down to $340 \mathrm{~K}$ is almost linear in the pre-glass transition region. At $620 \mathrm{~K}$ the heat capacity corresponds to about $300 \mathrm{JK}^{-1} \mathrm{~mol}^{-1}$, which is significantly higher than the Dulong-Petit heat capacity values. Indeed this behaviour is quite similar to that of silver pyrophosphate glass investigated by us earlier (Ananthraj et al 1986). The excess heat capacity (higher than the Dulong-Petit value) in the glassy region can be of configurational origin and like in silver pyrophosphate glass, could be due to the presence of a variety of anionic species originating from structural disproportionation of pyrophosphate groups discussed later in this section. Disproportionation can be quite facile and appears to occur quite extensively leading to the formation of a variety of anionic species. 


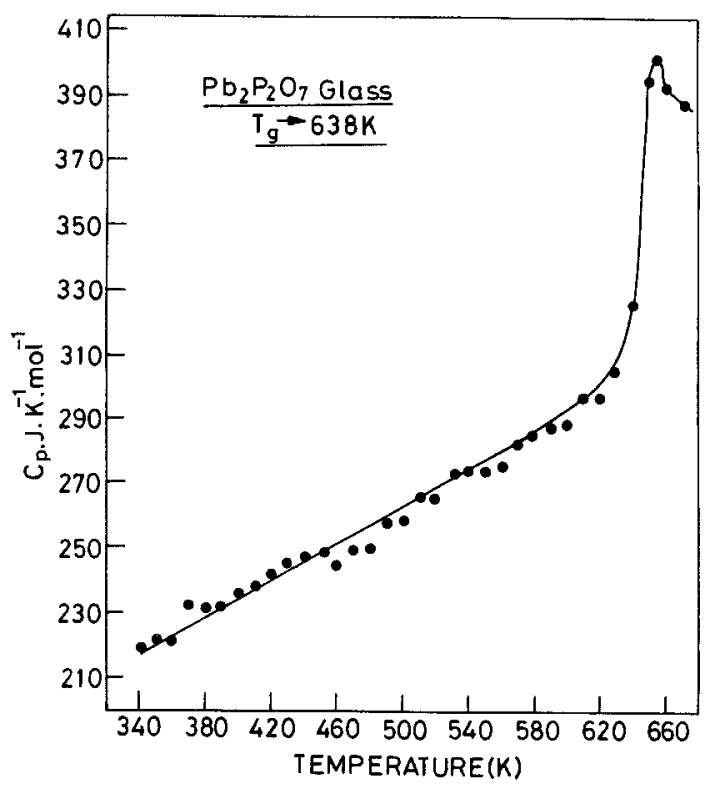

Figure 5. Heat capacity of $\mathrm{Pb}_{2} \mathrm{P}_{2} \mathrm{O}_{7}$ glass as a function of temperature.

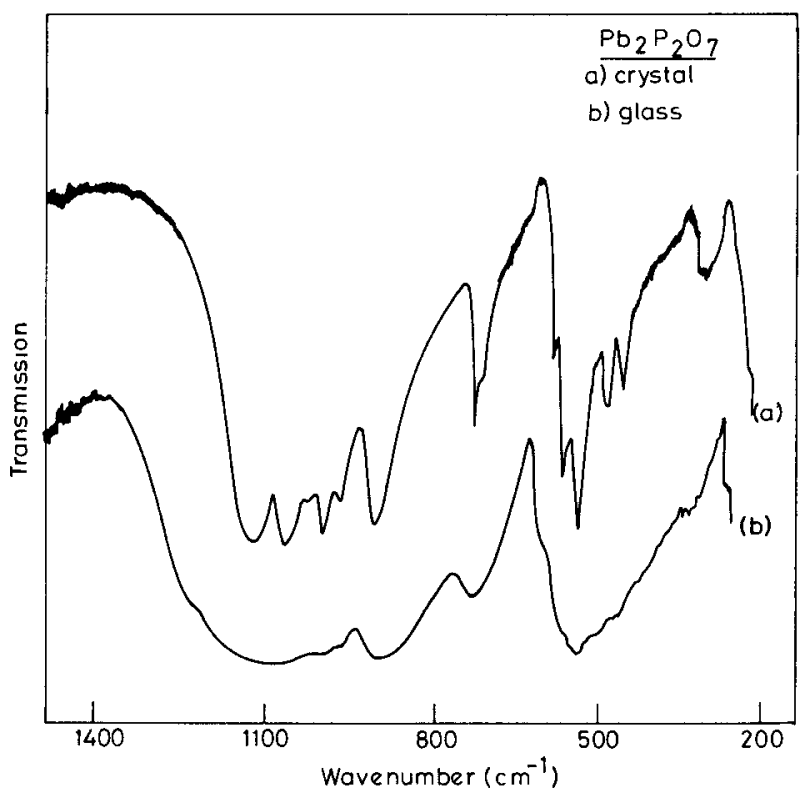

Figure 6. IR transmission spectra of $\mathrm{Pb}_{2} \mathrm{P}_{2} \mathrm{O}_{7}$ (a) crystal and (b) glass.

\subsection{Infrared studies}

The infrared spectra of the glassy and crystalline lead pyrophosphate are presented in figure 6. As one would expect, the rich vibrational features present in the pyrophosphate crystal due to the low symmetry of the triclinic $(P \overline{1})$ structure of the crystal (Brixner 1973), are smeared out in the spectra of the glassy form. Some of the 
principal absorption bands are, however, retained in the glass spectrum, e.g. the broad absorption bands centred around $1100,870,760$ and $520 \mathrm{~cm}^{-1}$, all of which are assigned to phosphate ions. For the glass an absorption band is observed at $717 \mathrm{~cm}^{-1}$ which is generally attributed to $\mathrm{P}-\mathrm{O}-\mathrm{P}$ bending in phosphorus-oxygen ring structures. This significant feature suggests the presence of anions with ring structures in the glass. The absorption band in $650-750 \mathrm{~cm}^{-1}$ is nevertheless broad. The pronounced shoulder to the high frequency side of the $1100 \mathrm{~cm}^{-1}$ absorption band confirms the formation of orthophosphate anions in the same manner as in silver pyrophosphate glass (Ananthraj et al 1986). However no yellow colour was observed in the lead pyrophosphate glass as in the case of glassy silver pyrophosphate. Therefore IR spectra of glasses also provide supportive evidence for the presence of several anionic species in the glass in addition to pyrophosphate which we show later is a consequence of anion disproportionation.

\subsection{Electrical conductivity}

The presence of a variety of phosphate anions is expected to generate a plurality of environment of $\mathrm{Pb}^{2+}$ cations and therefore ionic conductivity of the pyrophosphate glass was considered to be worthy of interest.

In figure 7 is shown the $\sigma_{\mathrm{AC}}$ conductivity of the lead pyrophosphate glass measured at $100 \mathrm{kHz}$ frequency as a function of temperature. In the inset to figure 7 , is the frequency response of the conductivity at laboratory temperature $(300 \mathrm{~K})$ for the same sample coated with gold electrode. There is very little dispersion in conductivity as a function of frequency above $10 \mathrm{kHz}$ although there are indications of rapid rise in conductivity towards much lower frequencies. In the frequency-independent region also, the conductivity is surprisingly little affected by temperature almost upto $T_{g}$. Therefore the conductivity activation barrier is very low. Since the magnitude of the

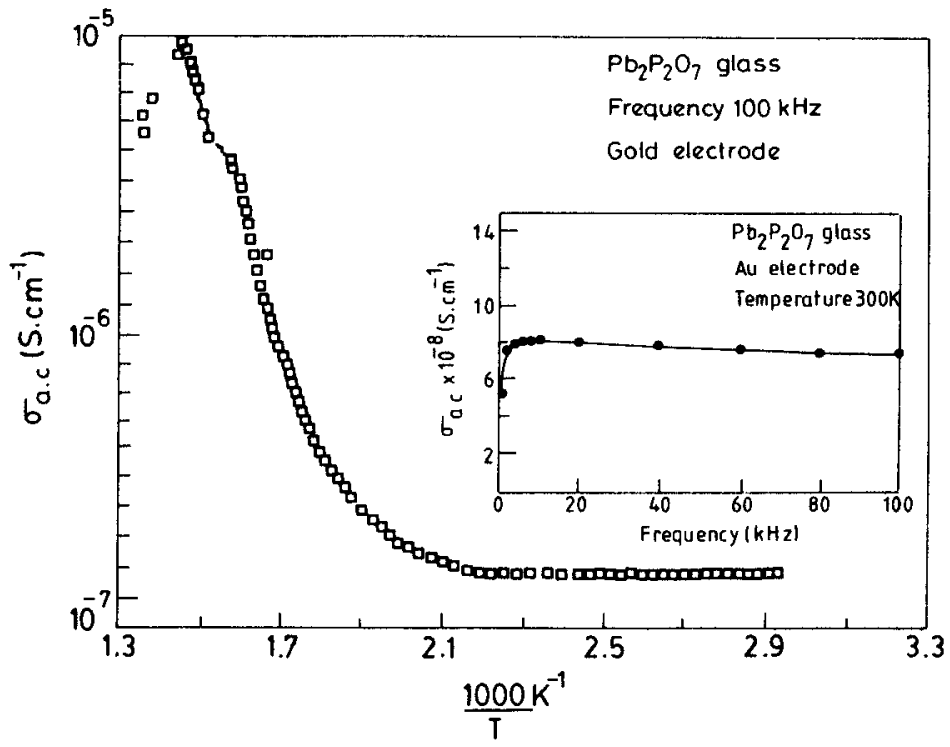

Figure 7. Temperature dependence of $\sigma_{\mathrm{AC}}$ conductivity for $\mathrm{Pb}_{2} \mathrm{P}_{2} \mathrm{O}_{7}$ glass (inset: variation of $\mathrm{AC}$ conductivity as a function of frequency at $300 \mathrm{~K}$ ). 
conductivity is low, the number of charge carriers should also be significantly low. A low magnitude of $\sigma_{\mathrm{AC}}$ which is also essentially unaffected by temperature, suggests that perhaps only a fraction of the lead ions are involved in electrical transport and also that the motion of these ions occurs in rather open and connected voids in the glass structure (low activation barrier). We tentatively infer that the remaining (large fraction) lead ions are present in network positions, as is their wont and are mostly immobile. This is a feature different from what we observed in silver pyrophosphate glass (whose properties we have compared all through) because the silver ions in the latter do not posses any tendency for network formation. On the contrary, the charge on silver ions in the glasses is lower than their formal charges and they give rise to fast ion conduction since they are "unpinned" from the potential well (Shastry et al 1989). The conductivity behaviour of lead pyrophosphate is therefore consistent with the possible presence of anions of different sizes which enable formation of the necessary open structure for the motion of a small proportion of $\mathrm{Pb}^{2+}$ ions which experience low activation barrier.

\subsection{Structural disproportionation model}

We now wish to address the question of how the pyrophosphate glasses give rise to the required structural entities whose presence, as we noted in the previous section, consistently explains the observed thermal, spectroscopic and electrical transport properties. We feel that the formation of many anionic species is a consequence of disproportionation reactions. The basic step in the structural disproportionation of pyrophosphate anions is,

$$
\begin{aligned}
& \mathrm{P}_{2} \mathrm{O}_{7}^{4-} \rightleftharpoons \mathrm{PO}_{3}^{-}+\mathrm{PO}_{4}^{3-} \text {. }
\end{aligned}
$$

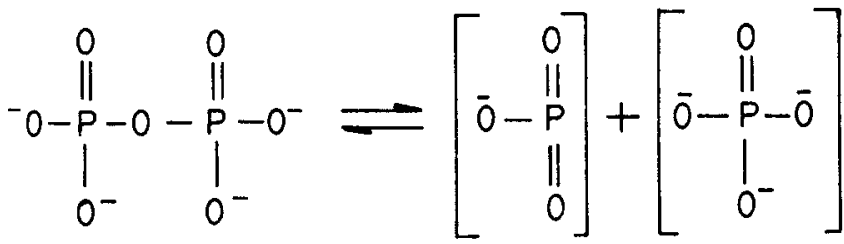

We may note that $\mathrm{PO}_{3}^{-}$ion acts as the primary building unit (a "synthon") for further polymerization as visualized as below.

$$
\mathrm{P}_{2} \mathrm{O}_{7}^{4-}+\mathrm{PO}_{3}^{-} \rightleftharpoons \mathrm{P}_{3} \mathrm{O}_{10}^{5-}
$$<smiles></smiles>

$$
\mathrm{P}_{2} \mathrm{O}_{7}^{4-}+n \mathrm{PO}_{3}^{-} \rightleftharpoons\left[\mathrm{P}_{2+n} \mathrm{O}_{7+3 n}\right]^{(4+n)-} \text {. }
$$

Further $\mathrm{PO}_{3}^{-}$can itself polymerize to ring structures like,

$$
3 \mathrm{PO}_{3}^{-} \rightleftharpoons \mathrm{P}_{3} \mathrm{O}_{9}^{3-}
$$




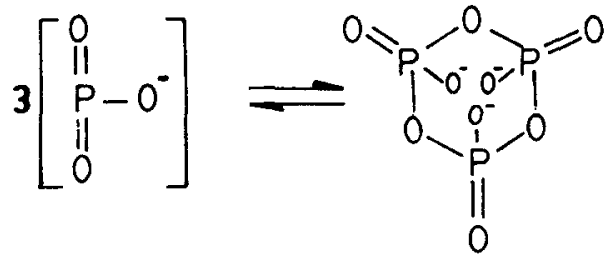

consisting of $4,5 \cdots P-O-P$ linkages. The reaction represented by (1) need not occur as a separate step. It can occur via a concerted reaction.

$$
\mathrm{P}_{2} \mathrm{O}_{7}^{4-}+\mathrm{P}_{2} \mathrm{O}_{7}^{4-} \rightleftharpoons \mathrm{P}_{3} \mathrm{O}_{10}^{5-}+\mathrm{PO}_{4}^{3-} \text {. }
$$

These reactions are evidently facile and therefore the thermodynamic and kinetic barriers involved in disproportion must be low. Since the total number of bonds and charges are fully conserved in disproportionation, to a first approximation the absence of a thermodynamic barrier is quite consistent. Similarly switching bonds as required for the structural rearrangement is also conceivably easy and hence the apparently low kinetic barrier. However, ${ }^{31} \mathrm{P}$ chemical shifts in the three types of phosphates, meta, pyro and ortho, are significantly different. Charge-related factors may therefore be expected to influence the disporprotionation. We have examined whether the disproportionation reaction disturbs seriously the local balance of electronegativities. In doing so, we recognize that electronegativity is a well-accepted chemical parameter and assume that electronegativity difference is a major driving force for chemical reactions. We have calculated, by Sanderson's (1983) method, the group electronegativities of the various phosphate anions, which we consider likely to result from disproportionation reactions and which are also known to be present in stable phosphates (Carbridge 1974). The procedure ensures that correct values of the formal charge on the anions are obtained. Since the electronegativities directly measure electron-accepting capacities, they also represent a direct measure of Lewis acidity or an inverse measure of the basicities of anions. In any multi-anion or multi-cation system at equilibrium, there always exists a difference in electronegativities of the ions. We make the plausible assumption that there exists a limit to such differences, which when exceeded leads to phase separation. In the pyrophosphate glasses, the primary step in the formation of various anionic species in the glass is represented by (1), and two anion species $\left(\mathrm{PO}_{3}^{-}\right.$and $\left.\mathrm{PO}_{3}^{4-}\right)$ of dissimilar electronegativities are formed. We consider that the difference between the electronegativities of the two species represents the maximum electronegativity differences which can be tolerated in the phosphate glass system. The two electronegativity values are 2.614 $\left(=\chi_{\mathrm{PO}_{j}}\right)$ and $1.661\left(=\chi_{\mathrm{PO}_{-}^{-}}\right)$. The electronegativity of $\mathrm{P}_{2} \mathrm{O}_{7}^{4-}$ itself is 2.087 . Thus any stable anion species should possess a $\chi$ lower than 2.614 and higher than 2.087 . We have listed the $\chi$ values of various well-characterized phosphate anion species and their electronegativities in table 1 . It is seen that the only anionic species whose $\chi$ values are lower than that of $\mathrm{PO}_{3}^{-}(2.614)$ are $\mathrm{P}_{3} \mathrm{O}_{10}^{5-}, \mathrm{P}_{4} \mathrm{O}_{13}^{6-}, \mathrm{P}_{5} \mathrm{O}_{16}^{7-}$ and $\mathrm{P}_{6} \mathrm{O}_{18}^{6-}$ [which is the same as $\left(\mathrm{PO}_{3}^{-}\right)_{6}$ ] and $\mathrm{P}_{2} \mathrm{O}_{7}^{4-}$. Hence we feel that they are the only anionic species which can be present in the glass.

The important point we wish to make is, although any number of linear phosphate anions tending towards an oxygen: phosphorus ratio of 3:1 can be conceived, they are not formed because in the phosphate melts such chains use the opportunity of 
Table 1. Electronegativities, partial charges on phosphorus and oxygen atoms of various known phosphate anionic species.

\begin{tabular}{lccc}
\hline $\begin{array}{l}\text { Phosphate } \\
\text { anionic } \\
\text { species }\end{array}$ & $\chi_{\mathrm{av}}$ & $\begin{array}{c}\text { Partial charge } \\
\text { per phosphorus } \\
\text { atom }\end{array}$ & $\begin{array}{c}\text { Partial charge } \\
\text { Per oxygen } \\
\text { atom }\end{array}$ \\
\hline $\mathrm{PO}_{3}^{-}$ & 2.6139 & 0.0397 & -0.3465 \\
$\mathrm{PO}_{4}^{3-}$ & 1.6606 & -0.3431 & -0.6642 \\
$\mathrm{P}_{2} \mathrm{O}_{7}^{4-}$ & 2.0866 & -0.1720 & -0.5227 \\
$\mathrm{P}_{3} \mathrm{O}_{10}^{5-}$ & 2.2495 & -0.1056 & -0.4680 \\
$\mathrm{P}_{4} \mathrm{O}_{13}^{6-}$ & 2.3355 & -0.0721 & -0.4393 \\
$\mathrm{P}_{5} \mathrm{O}_{16}^{7-}$ & 2.3886 & -0.0507 & -0.4216 \\
$\mathrm{P}_{6} \mathrm{O}_{18}^{6-}$ & 2.6139 & 0.0397 & -0.3465 \\
$\mathrm{P}_{10} \mathrm{O}_{27}^{4-}$ & 2.9945 & 0.1928 & -0.2195 \\
$\mathrm{P}_{13} \mathrm{O}_{37}^{9-}$ & 2.8023 & 0.1154 & -0.2838 \\
$\mathrm{P}_{14} \mathrm{O}_{40}^{10-}$ & 2.7884 & 0.1098 & -0.2884 \\
\hline
\end{tabular}

Table 2. The molecular electronegativities of various lead phosphates.

\begin{tabular}{lc}
\hline $\begin{array}{l}\text { Variety of lead } \\
\text { phosphates }\end{array}$ & $\begin{array}{c}\text { Molecular } \\
\text { electronegativities }\end{array}$ \\
\hline $\mathrm{Pb}\left(\mathrm{PO}_{3}\right)_{2}$ & $3 \cdot 1926$ \\
$\mathrm{~Pb}_{2} \mathrm{P}_{2} \mathrm{O}_{7}$ & $3 \cdot 1359$ \\
$\mathrm{~Pb}_{3}\left(\mathrm{PO}_{4}\right)_{2}$ & $3 \cdot 0965$ \\
$\mathrm{~Pb}_{5}\left(\mathrm{P}_{3} \mathrm{O}_{10}\right)_{2}$ & $3 \cdot 1528$ \\
$\mathrm{~Pb}_{6}\left(\mathrm{P}_{4} \mathrm{O}_{13}\right)_{2}$ & $3 \cdot 1617$ \\
$\mathrm{~Pb}_{7}\left(\mathrm{P}_{5} \mathrm{O}_{16}\right)_{2}$ & $3 \cdot 1677$ \\
\hline
\end{tabular}

cross-linking and are readily converted to rings. Thus it severely limits the size of the anion. Only a few anionic species are therefore produced in the pyrophosphate melt as is indeed evident from HPLC reports (Sales et al 1987).

Pyrophosphate glasses are therefore equivalent to a glass obtained by melting together various phosphates in appropriate proportions. The equilibration which occurs in the phosphate melt could also be considered as a consequence of their similar molecular electronegativities. The molecular electronegativities of the formula units of various phosphates are given in table 2 and were computed as the geometrical mean of the electronegativities of the component atoms in the formula. When molecular electronegativities are similar there is no enthalpic drive for any chemical reaction (Nagarajan and Rao 1990).

We therefore conclude from a consideration of electronegativities that (i) only a few anionic species would be generated in the melt as a result of structural disproportionation of pyrophosphate anions followed by polymerization in which $\mathrm{PO}_{3}^{-}$acts as a polymer synthon, (ii) ready equilibration of the different phosphates in the melt occurs due to their very similar electronegativities or basicities (inverse of electronegativities). 


\section{Experimental observations reconsidered}

We may note here that production of various anions coincidentally produces a large concentration of orthophosphate units. Since the oxygen atoms in orthophosphate ions carry the highest partial charge, $\mathrm{Pb}^{2+}$ ions tend to crowd around orthophosphate units. The crowding immobilizes significant numbers of lead ions in the neighbourhood of orthophosphate units. Further orthophosphate ions (and to some extend pyrophosphate ions) enable tight structural packing around themselves, which enhances the barrier for migration of lead ions. Lead ions are also immobilized when they occupy network positions through reactions of the type.

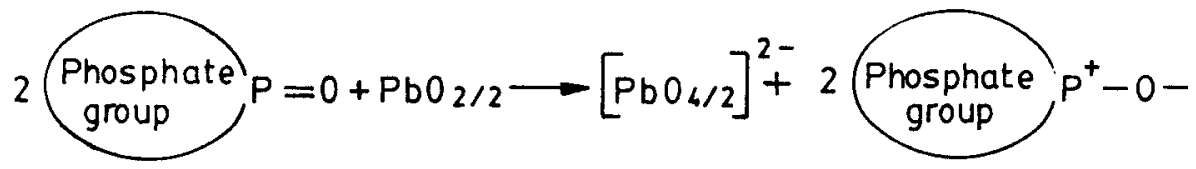

Equation (4), appears as if lead oxide acts as an acid and reacts with phosphate anions which are conjugate bases. Such incorporation of lead into network positions has been noted by us in lead phosphomolybdate glasses (Rao et al 1986; Selvaraj and Rao 1988; Damodaran et al 1988). It would therefore be reasonable to assume that significant fractions of lead ions are present in four coordinated network positions and are therefore immobilized. Thus the net fraction of free $\mathrm{Pb}^{2+}$ ions is low and these are the only ones which can contribute to transport properties, and occupy voids present in the inefficiently packed regions. The large phosphate ions possess topologically restrictive geometries and therefore give rise to inefficiently packed regions. The conductivity behaviour observed in figure 7 , is therefore consistent with the motion of a small fraction of lead ions in large voids created in the polymerized anionic matrix, and hence the activation barriers are low. The conductivity itself has a low magnitude because of their small number.

As noted by us in the case of silver pyrophosphate glass (Ananthraj et al 1986), large configurational entropy results from the multiplicity of anionic species and gives rise to high values of heat capacity in the glassy region. The presence of $\mathrm{Pb}^{2+}$ ions in network and non-network positions may also contribute to the configurational heat capacity.

In our studies we have also noted that although lead metaphosphate glass is soluble in water, lead pyrophosphate glass is completely insoluble. Indeed, we use this property to precipitate lead pyrophosphate. We have therefore examined the electronegativities of the phosphate anions and lead cations vis-a-vis the electronegativity of water itself. Lead ions possess an electronegativity of $2 \cdot 376$, which is slightly higher than but close to the value for $\mathrm{P}_{2} \mathrm{O}_{7}^{4-}$ ions. While it is lower than that for $\mathrm{PO}_{3}^{-}$ions $(2 \cdot 614)$, it is significantly higher than that for the $\mathrm{PO}_{4}^{3-}$ ions $(1 \cdot 661)$. Water has an electronegativity of 2.60. Thus the electronegativities of cations and anions are best matched in pyrophosphate (Brown 1980), which may be the reason why lead pyrophosphate glass, which largely consists of $\mathrm{P}_{2} \mathrm{O}_{7}^{4-}$ ions, is least soluble in water. Its absence makes the metaphosphate soluble in water particularly in view of the similarities of the electronegativities of water and meta phosphate ions.

In conclusion we wish to add that a vital chemical parameter like electronegativity, whose quantum chemical origin is well-established can be quite effectively used in 
understanding the formation, stability and transport behaviour in pyrophosphate glasses.

\section{Acknowledgements}

The authors wish to thank Prof C N R Rao, FRS, for his kind encouragement. Help given by $\mathrm{Mr} \mathrm{G} \mathrm{N}$ Subbanna in electron microscopic studies is warmly acknowledged.

\section{References}

Ananthraj S, Varma K B R and Rao K J 1986 Mater. Res. Bull. 211369

Ananthraj S, Varma K B R and Rao K J 1988 Solid State Ionics 275

ASTM Cards Files No: 6-0269

Brixner L H, Bierstedt P E and Foris C M 1973 J. Solid State Chem. 6430

Brown D B 1980 in Mixed valence compounds (Holland)

Carbridge D E C 1974 in The structural chemistry of phosphorus (Amsterdam: Elsevier)

Damodaran K V, Selvaraj U and Rao K J 1988 Mater. Res. Bull. 23151

Nagarajan V S and Rao K J 1990 J. Solid State Chem. 88419

Prabhakar S, Rao K J and Rao C N R 1987 Chem. Phy. Lett. 13996

Rao K J, Rao B G, Selvaraj U and Damodaran V 1986 Collected Papers Int. Conf. on Glass, New Delhi Sales B C, Boatner L A and McCallum 1987 Phys. Rev. Lett. 591718

Sales B C, Ramey J O, Boatner L A and McCallum 1989 Phys. Rev. Lett. 621138

Sanderson R T 1983 in Polar covalence (London: Academic Press)

Selvaraj U and Rao K J 1988 J. Non-Cryst. Solids 104300

Shastry M C R and Rao K J 1989 Solid State Ionics 3717

Van Wazer J R 1958 in Phosphorus and its compound chemistry (New York interscience) vol. 1, chap. 12 